\title{
La amistad, san Agustín y la actualidad
}

\section{(Comentario amistoso)}

La ocasión de este comentario nos la ofrece un libro de reciente publicación sobre «La amistad en la vida religiosa» ${ }^{1}$. Aunque el título anuncia un tema teorético, va ligado a otro tema histórico y a otro de actualidad. De los ocho capítulos de que consta el libro, siete son dedicados a san Agustín y uno solo, el último, ofrece unas consideraciones generales. En cuanto a la preocupación por la situación actual, se revela en muchas páginas y se expone más detalladamente en un artículo posterior del mismo autor ${ }^{2}$, que ya levanta un airecillo de réplica.

Los tres temas debieran tratarse por separado parà evitar confusión. En cuanto al primero, ¿qué es la amistad? Es un fenómeno social, que todos conocen y sin embargo es un misterio: en todo caso deberá tratarse con los métodos de la fenomenología y de la aporética, como cualesquiera temas de ese género. También el tema histórico de la amistad en san Agustín deberá tratarse con métodos históricos. $\mathrm{Y}$ en cuanto a la relevancia y actualidad de la amistad en las comunidades religiosas, hay también métodos apropiados. De otro modo, ya tenemos a la vista la confusión. Nada más publicarse el libro de Viñas, salió a la palestra el P. Luciano Rubio, defendiendo que «el ideal monástico» de san Agustín era la comunidad de bienes ${ }^{3}$. No nos parece acertada la proposición del P. Rubio, pero es provocada por el libro de Viñas, que identifica «ideal monástico» con «carisma fundacional». Esto indica que todos tendrían derecho a opinar, y volveríamos a las inútiles discusiones sobre el carácter del monaquismo agustiniano, en las que cada autor planteaba y resolvía el proble-

1. VIÑAS, R.T., La amistad en la vida religiosa, Madrid 1982.

2. VIÑAS, R.T., «Vida religiosa y amistad» en La Ciudad de Dios, 194 (1983) 377-408.

3. Rubio, L., El ideal monástico de san Agustín y otras cuestiones anejas», en La Ciudad de Dios, 196 (1983) 3-58. 
ma desde su punto de vista. Y ninguno de nosotros tendría toda la razón, ya que san Agustín no es el fundador de una Orden religiosa, sino un Padre de la Iglesia y un genio de la humanidad. ¿Desde qué punto de vista hay que estudiar sus temas? Además, Agustín evolucionó y progresó mucho en su concepción del monaquismo. ¿A qué época deberemos referirnos? Finalmente, ¿podemos identificar un «carisma fundacional, con un ideal monástico, con una realidad monástica, con un carácter fundadional, con una causalidad, con una finalidad?, etc. El empeño de simplificar, reuniéndolo todo o reduciéndolo todo a un concepto, nos perjudica, ya que al final no sabemos cuál es el pensamiento concreto de Agustín.

En este comentario nos acomodamos al libro de Viñas, como es natural, pero distinguiremos los aspectos diferentes de esa relación amistosa que él quiere simplificar con exceso. Es ya muy antigua la preocupación de los llamados «Agustinos» por su problema de identidad, pero las recomendaciones del Vaticano II obligan a repasar la historia. La Orden de Ermitaños de san Agustín tuvo que reformar sus constituciones en 1968. Entonces fue el momento propicio de tomar una postura definida.

Que san Agustín haya fundado a los «agustinos» es un error histórico sin importancia especial. El misal, el breviario, la hagiografía y la historia están plagados de tales errores históricos que no escandalizan a nadie. Nadie se escandaliza de la devoción que los ingleses y los catalanes tienen a san Jorge, de la devoción de los medievales por el sepulcro de Santiago en Compostela o de la venida de la Virgen a Zaragoza en carne mortal, etc., etc. Pues bien, los Ermitaños de san Agustín, que fueron reunidos en una Orden en 1256, creyeron desde un principio que san Agustín era su fundador. Surgieron leyendas sobre una vida eremítica del santo en Toscana, nacieron unos Sermones ad Fratres in eremo y por todos los medios se trató de justificar esa creencia, que pasó a ser como un dogma. Las discusiones con los Canónigos Regulares de san Agustín, y las contiendas con otras Órdenes, contribuyeron a afianzar la creencia. Llegó un momento en que el negar tal creencia fue una auténtica herejía. En virtud de esa creencia, los miembros de esta Orden estudiaron especialmente a san Agustín, se empaparon en su espíritu, cobraron una originalidad y una personalidad inconfundibles y finalmente podría decirse que deben a san Agustín casi todo lo bueno que la Orden produjo a lo largo de los siglos.

Pero como se trata de un error histórico, llegó un momento en que la crítica hubo de reaccionar y establecer, como realidad histórica, que los tales «Agustinos» nacieron en 1256, en el ambiente de las Órdenes mendicantes, con un espíritu apostólico de «mendicantes», y con una espiritualidad de «mendicantes». Surge así un conflicto inevitable con la tradición de la Orden. La reforma de las constituciones de 1968 parecía la coyuntura propicia para 
fijar la opción. El discurso con que el P. General, Agustín Trapé, inauguraba el Capítulo, parecía decisivo, ya que optaba por san Agustín sin distingos ni reservas medievales. Pero previamente se había constituido en Roma una comisión encargada de anteponer a las constituciones una primera parte sobre el espíritu de la Orden. Así que prevaleció el criterio histórico y jurídico sobre el espiritual, y se redactaron unas «Constituciones de los Hermanos de la Orden de San Agustín». El discurso del P. General se quedó en letra muerta. Las ambigüedades, lejos de cesar, han aumentado, y el problema de la identidad se ha hecho más grave. Ni siquiera se discutió qué criterio debía prevalecer, y la tradición secular de nuestros padres quedó truncada. San Agustín, en lugar de ser una fuente de espiritualidad para la Orden, se convirtió en un monumento arqueológico, en un sepulcro como el de Pavía, encomendado a los «Agustinos». Los que, como el P. Viñas y tantos otros, tratan de asimilarse la espiritualidad de san Agustín, fluctúan indecisos entre el Imperio Romano y el Sacro Imperio Germánico. La nuestra es, pues, una Orden de «fraternidad apostólica», que se denomina con toda propiedad «Orden de los Hermanos de San Agustín» ${ }^{4}$.

El problema es, pues, áspero. Al no discutirse ni aclararse cuál es la espiritualidad de san Agustín, cuáles sus líneas fundamentales, cuál su sistema, cuál su espíritu, carecemos de un contexto general, para situar la doctrina agustiniana en los puntos concretos. Porque aquí no se trata de resolver un problema histórico puro. Si la Iglesia de Cristo es algo más y mejor que un problema histórico, también la Orden agustiniana es algo más y mejor que un problema histórico. Es preciso respetar la historia y sus problemas, pero aquí se trata de reconocer y asimilar el espíritu de un fundador putativo, según la tradición de nuestros Padres. La misma Biblia tiene además del sentido literal y del figurado un sentido "acomodaticio», perfectamente legítimo, que la Iglesia utiliza con una consciencia clara y firme. Eso mismo haremos nosotros en el ejemplo y la doctrina de san Agustín, sabiendo perfectamente a qué atenernos, sin «medievalismos» y sin incurrir en errores históricos. Y esto debería ser, no solo una recomendación, sino también un deber histórico y una lealtad a nuestros Padres.

El prólogo del P. Turienzo, que encabeza el libro, plantea algunas reservas y así plantea al mismo tiempo un problema como Quaestio. «¿Quién escribe hoy, pregunta Turienzo, un tratado sobre la amistad?». Y al final del prólogo, él mismo se responde: «acaso es llegado el momento de ponerse a escribirlo». Perfectamente. Porque tenemos ya de salida la definición clásica de la

4. Const. cap. I, nn. 4 y 5 . 
amistad: «es coincidencia en los asuntos sagrados y profanos, con benevolencia y caridad». Esta no es en realidad una definición, pero obliga a pensar en algún tipo de definición o fijación de un punto de partida. Concebiremos, pues, la amistad como relación amorosa entre dos personas, que ponen como fundamento de esa relación la «amabilidad» de las mismas personas. Teóricamente se ama pues a un amigo o amiga simplemente porque es amable, porque nos encanta su amabilidad. Esto nos sirve para eliminar cualesquiera otros tipos de relaciones: la sexual, erótica, estética, familiar, profesional, burocrática, económica, comercial, utilitaria, religiosa, proselitista, convencional. Sin embargo, prácticamente la amistad puede producirse en todas estas clases de relaciones y de ahí puede provenir una cierta confusión.

Esa confusión puede producirse también por otro motivo. Cuando se trata de nuestra relación religiosa con Dios, podríamos pensar que el amor de amistad era un fin en sí mismo. Pero cuando se trata de relaciones humanas, la amistad es un medio y no un fin en sí misma. Se ama al amigo, pero siempre con alguna otra finalidad, como aparece en la definición clásica. Buscamos la felicidad, la virtud, algún valor superior, una causa común. Se presenta, pues, la amistad como un «tú a tú», pero en la vida real no puede producirse sin adherencias y circunstancias concretas. $Y$ por eso la amistad tiene una serie de funciones específicas. El amigo es consejero, colaborador, confidente, copartícipe, comprometido, consolador, escudero, animador, etc. Como en todo amor, hay aquí un misterio. El amigo vive en sí mismo, pero vive también en su amigo: «vivo sin vivir en mí». La amistad supone igualdad entre dos personas, pero en la práctica esa igualdad es imposible.

Según la definición clásica tenemos una coincidencia en los asuntos sagrados y profanos. La añadidura «con benevolencia y caridad» parece mera tautología. ¿Qué sentido tiene esa coincidencia en los asuntos sagrados y profanos, ese acuerdo de los amigos en los problemas de la vida? Turienzo estima que se trata de un sentido de la aristocracia olímpica de los sabios, y por lo mismo tal definición ni convence ni interesa al hombre actual. Sin embargo hay que remontarse a la época en que los «sabios» tenían que abandonar las creencias populares. ¿Cómo podía un sabio aceptar el Olimpo con las juergas divinas de Homero? Plutarco llegó a decir: «vomita los mitos y enjuágate la boca». Pero entonces el pueblo condenó a esos sabios o «filósofos», como enemigos de los dioses y de los hombres. Los sabios (pensemos en los órficos y pitagóricos) fueron perseguidos, torturados, masacrados por las turbas y por las jerarquías ciudadanas. Para defenderse, esos sabios formaron círculos, cenáculos secretos, reuniones o «sectas», en las que podían predicar sus doctrinas y encontrar un público en el que había «coincidencia en los asuntos sagrados y profanos». Todavía Platón, en la Apología de Sócrates, da testimonio 
de la importancia que tenía la amistad como defensa personal y como cauce de propagación de las doctrinas.

Es, pues, creíble que en el fondo, ese sentido de la amistad convence e interesa al hombre actual, que también tiene que defender su personalidad cuando no su misma vida, y recurrir a organizaciones más o menos secretas de difusión del pensamiento. De hecho, nuestra actualidad está multiplicando las sectas por motivos bastante más fútiles y circunstanciales. Quizá en Cicerón la definición de la amistad era ya una simple resonancia retórica, pero san Agustín la tomó muy en serio, él venía de una secta, el maniqueísmo, sabía lo que significaba el secreto, y cuán necesaria era la coincidencia en los asuntos sagrados y profanos para el individuo y para la comunidad.

No puede negarse la tendencia de la actual sociedad de consumo a disolver los vínculos orgánicos tradicionales. Pero eso no significa que debamos dejarnos arrastrar por esa tendencia, y más bien deberemos resistir y oponernos a ella por muchas razones.

\section{LA DIMENSIÓN PSICOLÓGICA}

La amistad no puede perder actualidad. Si en los tiempos de Sócrates y Cicerón respondía a una situación de ocio y élite, propio de la sociedad grecorromana, en principio responde a una necesidad humana de los individuos y de las comunidades. Porque en todo individuo está ya planteado el juego entre el egoísmo y el amor, entre el anonimato y el personalismo. Eso mismo acontece en los grupos entre el «nosotros» y el «ellos».

En la actualidad se han elevado esas tensiones. Porque la sociedad de consumo promueve la organización, la administración, la industrialización, la urbanización, la institución. Así surge una ofensiva contra la amistad comprometida o seria, como también contra el matrimonio o los votos religiosos, contra todo vínculo estable y orgánico que signifique una dependencia personal. Así fue eliminado el derecho germánico para implantar el derecho romano, que es calificado de ocio y élite. Se venden máscaras para salir a la calle y fachadas para defenderse de las miradas indiscretas. «Mi casa es mi castillo». La propaganda multiplica las reservas. ¿Un amigo formal? Puede morir o enfermar, alejarse o convertirse en enemigo, delator, espía, control, dictador, sombra maléfica, yugo. El hombre actual cree haber logrado su madurez e independencia. Aunque es incapaz de vivir en soledad consigo mismo y de ponerse al servicio del prójimo, se siente bien a solas y a sus anchas en las avenidas de una ciudad desconocida: el hijo de familia se siente liberado cuando ingresa en el cuartel y se convierte en un número. También se siente bien a sus anchas cuando se grita en medio de la muchedumbre en un partido de fútbol. 
Pero así se esconde el aguijón de su inquietud. Del fondo del abismo humano sube la voz de la conciencia, la voz de la vocación. El hombre, «arrojado al mundo y perdido en él», se vuelve anónimo: paladea la náusea de Sartre, la extranjería de Camus, la sensación del absurdo, la frustración de la vida inauténtica, el vértigo del nihilismo, la vaciedad y aburrimiento del pasotismo, o la impotencia que empuja al suicidio. El pasota echa la culpa de su indeterminación a la amenaza de la bomba atómica, pero sabe que es una mera excusa: porque la muerte nunca ha olvidado sus deberes, y todos los hombres han muerto o mueren o tienen que morir. La reacción frente al anonimato y al desamparo es muy variada, pero así surgen con frecuencia la envidia hacia los que tienen «ideales» o a los que en su grupo hallaron el sentido de su vida. Por eso este hombre actual se siente condenado o bien a entrar en sí mismo, o bien a buscar un sentido social. Recurre a la compañía, a la aglomeración, al turismo, al espectáculo, a la masificación, a las pandillas, amigotes, amiguetes, partidos, discotecas, zarabandas, cruceros, movimientos, encuentros, se envuelve en relaciones, convivencias, uniones irresponsables, y cultiva la amistad de la que decía san Agustín etiam latrones habent caritatem! «Hasta los terroristas se tienen amor».

La preocupación de Agustín por este problema es notoria, como se ve en su librito sobre la Vida bienaventurada. Al parecer discutía con Manlio Teodoro sobre ese problema. Mientras Manlio Teodoro defendía que esa vida bienaventurada que buscan los amigos se debe a la fortuna (azar, destino, necesidad, casualidad), Agustín defendía que es un «don de Dios». Y si bien ambos tenían razón desde su punto de vista, la causa de la amistad es siempre profunda, arraigada en la misma condición humana.

En cuanto al problema histórico de Agustín, es harto complejo. De muchacho se juntó con amigotes, gamberros, robaperas, eversores, pero difícilmente se puede hablar de «amigos». Convertido al maniqueísmo, sus amigos fueron maniqueos. El «amigo» de Tagaste se hizo maniqueo por el proselitismo de Agustín y escuchaba admirado la conferencia cotidiana del maestro de gramática. Más que un amigo, ese joven parece una víctima del proselitismo y de la necesidad que tenía Agustín de tratar con alguien en su propia aldea, en la que se sentía «extranjero». De otro modo no entenderíamos por qué le causó un efecto tan fulminante al maestrillo el bautismo de su amigo y su muerte dentro de la Iglesia católica, hasta el punto de abandonar la aldea en busca de otros amigos maniqueos. $\mathrm{Y}$ eșo acontece con todos sus «amigos».

Era un burócrata en plena alienación burocrática, un modelo de cualificación técnica, cuyas relaciones eran profesionales y convencionales. Su sentido de la existencia podía extenderse desde la vanagloria por los triunfos profesionales hasta un escepticismo petulante por sus fracasos. Hasta podía envi- 
diar a un borrachín tirado en la calzada, pero satisfecho de haber encontrado en el fondo de una botella la felicidad que Agustín buscaba tan afanosamente ${ }^{5}$. Al convertirse al cristianismo cambia el fundamento de sus relaciones personales. Los amigos maniqueos dejan de ser amigos, mientras sus nuevos amigos son ahora los cristianos, las víctimas de su imperialismo religioso o los que resultan «útiles» para sus nuevos propósitos.

El platonismo le crea un conflicto radical, aunque al principio Agustín apenas lo advierte. Según el platonismo sería preciso despojar a los amigos de sus notas individuantes y convertirlos en una «idea inmortal»: es la consecuencia del esencialismo. Pero con la conversión, Agustín se introduce en un existencialismo, y ama a sus amigos tales como ellos son con todas su notas individuantes ${ }^{6}$. De todos modos, sus amistades son especiales. Además hay que tener en cuenta su estilo «retórico». Esas cartas, tan floridas a los amigos, suenan a retórica clásica y no se oponen a lo que estamos diciendo. Verecundo se queda atrás, mientras Evodio, un desconocido, avanza al primer plano. Alipio continúa porque sigue a Agustín como una sombra. Pero vemos cómo son preferidos los amigos por su utilidad, no por su amabilidad, como la amistad pediría: así Aurelio de Cartago, Marcelino, Bonifacio, reclaman su atención. Tomar al pie de la letra las expresiones afectuosas de Agustín sobre la amistad, parece un optimismo inocente, más que una demostración fehaciente. Así por ejemplo, después de la descripción apasionada que nos hace en las Confesiones sobre la muerte de su amigo de Tagaste, nos dice en las $R e$ tractationes: «Quizá temía morir yo, para que no muriera enteramente aquel, a quien yo había amado tanto» ${ }^{7}$ : esto me parece una declamación frívola, más bien que una confesión seria, aunque quizá esa «inepcia» quede suavizada con la partícula «quizá» ${ }^{8}$. Es, pues, peligroso tomar las expresiones «amigables» al pie de la letra.

Agustín es una paradoja viviente. Predica la soledad del corazón, invita a dejar el mundo y entrar dentro de sí, anima a buscar a Dios solo y la vida bienaventurada, a apartarse de la esfera sensorial, a penetrar en la región de las puras ideas y a vivir un platonismo cristianizado; nos predica una iglesia espiritual, que trae a mal traer a los teólogos, fomenta la interioridad, la espiritualidad, la introspección, el análisis del insconsciente, etc. Pero este hombre «seráfico» es puro amor. Su «vida bienaventurada» es trascendente y escatológica, metafísica; su Dios es un Dios social en Jesucristo, un Dios que congrega a

5. San Agustin, Confess. VI, 6,9, PL 32,724.

6. San Agustín, Epist. 2, PL 33,63.

7. Confess. IV, 6.

8. Retract. II, 6,2. PL 32,632. 
toda la humanidad. Agustín no sabe vivir solo. Vive siempre rodeado de amigos y enemigos, en continuo roce social, derramando a raudales su gracia personal. Pasa los días enteros a la puerta de la basílica distribuyendo la justicia entre los fieles, y las noches meditando y escribiendo para los demás. Mientras habla de una Iglesia espiritual, es un obispo jerárquico y puede repetir: «Soy un remero de la Iglesia». No es un inocente, ni se deja llevar de un natural demasiado débil. Conoce el divorcio de la amistad en personas tan relevantes y santas como Jerónimo y Rufino, y él interviene en favor de la amistad, como «defensor del vínculo», con unas páginas inmortales. La delicadeza de que hace alarde en sus relaciones amistosas, inclusó cuando discute con Alipio, es proverbial. Por muchos inconvenientes y reservas que el lector o el crítico amontone contra su psicología de propenso a la amistad, se ve abrumado por la simpatía y el calor humano. ¡Es un santo tan «humano»!

No podemos dudar de que tomaba en serio la definición clásica de la amistad, si bien la llenaba de un contenido cristiano. Y no caía en la sospecha de «meras retóricas» y declamaciones frívolas, ya que el maniqueísmo, en cuanto «secta», le había hecho vivir la necesidad de un secreto compartido, de un espíritu contagioso, de unas consignas y de una actitud defensiva frente a la opresión social. La definición clásica respondía, pues, perfectamente a su psicología proselitista, pero intimista. Es pues, para nosotros, un excelente modelo, ya que nos vemos situados aproximadamente en sus mismas circunstancias. Podemos, pues, muy bien rechazar el contenido de la definición clásica, y conservar la definición para llenarla de los contenidos actuales, ya que nuestra psicología desemboca siempre en sociología.

¿Qué diremos entonces de la psicología monástica de Agustín? El papel de la amistad parece quedar bien definido. Ante todo se trata de un hecho: los que colaboran en la «fundación» son ya amigos de hecho. El proyecto de Milán se hacía bajo la influencia de Pitágoras. Respondía a la definición clásica de la amistad. El ensayo de Casiciaco fue como un noviciado para redondear ese mismo proyecto con la experiencia y con las visitas a los monasterios ${ }^{10}$.

Agustín se convierte, no sólo al cristianismo, sino también al monaquismo. Aunque Ponticiano le había informado sobre la vida monástica y pudo verla en Milán y Roma, había algo más profundo y decisivo: los maniqueos convertían su moralidad en argumento apologético sobre la verdad y rectitud de su secta. Agustín parece reconocer que una religión verdadera ha de produ-

9. VerheiJen, L., Nouvelle approche de la Règle de S. Augustin, Abbaye de Bellefontaine, 1980, p. 201-243.

10. Camino, A.L., La comunidad de Casiciaco como grupo informal. La primera experiencia comunitaria de Agustín. Tesis dactilografiada, Salamanca 1977. 
cir santos necesariamente. Eso se había intentado con el ensayo que los maniqueos hicieron en Roma ${ }^{11}$. Agustín les arrebata el argumento, mostrando que la Iglesia católica es la que produce santos de verdad; el monaquismo se convierte así en argumento apologético, en santidad visible ante el pueblo. Se cambia, pues, el orden de los argumentos apologéticos: no se convierten los hombres por la fuerza del milagro o de la profecía, sino por el ejemplo de los santos que produce una religión; y cuando no los produce, evidencia o bien su inutilidad, o bien que no es vivida realmente. La institución de Agustín ostentaba, pues, la pretensión de mostrar al pueblo la «perfección cristiana».

Una nueva intención se descubre en el concepto de militia christiana ${ }^{12}$. Ese título de «siervos de Dios» podía tener sentido amplio como en el caso de Rufino, Pelagio, etc. Pero la fórmula de Apuleyo obligaba a Agustín a tomar el término en el contexto del ambiente romano, que llamaba «ejército sin armas» a todos los funcionarios del Estado, como eran los amigos de Agustín. Así Evodio se desciñe su fagín secular y se ciñe el de la militia de Cristo ${ }^{13}$; Agustín había reprochado a los católicos muchos crímenes durante su maniqueísmo y sabía que los maniqueos continuaban denunciando tales crímenes ${ }^{14}$. Por eso el concepto de militia christiana lleva ya en sí el propósito de un «reformador», que no sólo defiende a la Iglesia de los enemigos exteriores, sino también de los enemigos interiores, de los malos cristianos. El monaquismo está, pues, subordinado a valores más altos.

\section{LA DIMENSIÓN SOCIOLÓGICA}

Algunos críticos consideran a san Agustín fundador de la sociología, puesto que fue el primero en ver y explicar que una entidad social no es la suma de sus miembros, sino un organismo que tiene sus propias leyes de nacimiento, desarrollo y decadencia ${ }^{15}$. En todo caso la fundación monástica del santo es un excelente ejemplo de esa tesis: nació y se desarrolló por un principio vital interior, sin que el santo tuviera idea de lo que en el futuro iba a significar su institución. Nació en el ambiente del Imperio romano y es hoy para

11. SAn Agustín, De Mor. Ecclesiae, II, 20, 74, PL 32, 1376.

12. Cfr. Emonds, H., «Geistlicher Kriegdienst. Der topos der militia christiana in der Antiken Philosophie», en Festlhr. Herwegen 1938, pp. 21-50. Da nomen huic sanctae militiae, Apuleyo, Metamorph. XI, 15,25.

13. San Agustín, Confess. IX, 8,17, PL 32,771.

14. San Agustín, De Mor. Eccl. I,34,76 PL 32,1342.

15. Cf. Ziegenfuss, W., Augustinus. Christliche Trascendenz in Gesselschaft und Geschichte, Berlín 1948. 
nosotros una fuente de inspiración y de espiritualidad, que la sociología nos ayuda a actualizar, esto es, a traducir e interpretar.

Nuestra sociedad de consumo se caracteriza por un afán de asociación, que parece contradictorio, ya que por un lado disuelve los compromisos estables y por otro lado reclama una defensa de la personalidad y de la libertad personal ${ }^{16}$. Este desarrollo sociológico nos ha prestado un buen servicio, al analizar el concepto de «secta», eliminando su sentido peyorativo y dándole un prestigio inusitado. La secta se coloca entre los grupos de masificación y el aislamiento, entre las asociaciones gregarias y las asociaciones carismáticas. No todas las comunidades son sectas, ya que muchas se desvían hacia uno de los extremismos mencionados. La secta se distingue porque posee un Geist, un espíritu de contagio, de amistad y de fraternidad. Ofrece un ambiente de convivencia y un sentimiento de «nosotros», en oposición a ellos, que caracteriza hoy a muchas minorías. Jamás hubo en la historia tantas sectas y tan bien planeadas, tantas celebraciones a puerta cerrada, en las que el individuo personal pueda pronunciar el «nosotros» con orgullo, satisfecho de dar a su vida un sentido social y concreto y un valor real, realzado y establecido por el vínculo de la convivencia, de la fraternidad y de la unidad.

Parece que las comunidades religiosas deberían ser auténticas sectas modelo. $\mathrm{Y}$ de hecho en ellas se producen la amistad y las funciones de la amistad con mayor naturalidad y abundancia que en cualesquiera otros grupos humanos. Un hombre independiente como Th. Roszak ${ }^{17}$ se atreve a presentar las comunidades monásticas como paradigma y modelo en nuestra sociedad de consumo: en asociaciones semejantes aprenderían todos a vacunarse contra las dos grandes epidemias de nuestro tiempo, que son la intolerancia de la propia soledad y la indiferencia frente al prójimo.

Las antiguas «escuelas filosóficas» eran en realidad sectas, como lo entiende san Agustín: «eran entonces los estudios tan florecientes en las diferentes sectas, que sólo podía temerse la aprobación de doctrinas falsas» ${ }^{18}$. Expresamente se refiere a Pitágoras: «hoy has expuesto ante nuestros ojos la disciplina de Pitágoras...» ${ }^{19}$. Esa influencia preponderante de Pitágoras subraya la importancia de la amistad en la institución agustiniana, pues repite como norma: in omni vita, tempora, amicos aut habeat aut habere instent. Para Pitágoras la doctrina de la amistad era el resumen de toda su doctrina. Jámblico, al recoger la doctrina pitagórica sobre la amistad, utiliza la fórmula agusti-

16. Cfr. Von OpPen, Das personale Zeitalter, Stuttgart, 1965.

17. RoszaK, Person-Planet, N.Y., 1979.

18. San Agustín, Epist. 1,2, PL 32,62.

19. San Agustín, De Ordine, II, 20,53, PL 32,1020. 
niana «concordia espiritual» ${ }^{20}$. Siendo como eran ya amigos de hecho los candidatos de Agustín, ¿cómo no pensar que Agustín recogía la doctrina de Cicerón y de Varrón acerca de las sectas filosóficas antiguas y especialmente sobre Pitágoras? Su ideal consistía, pues, en cristianizar esa doctrina, en buscar, como siempre, una «religión racional», o filosófica. De este modo la amistad sin ser ningún carisma fundacional, ya que eso suena a teología, era una condición importante para lograr los fines de la institución monástica.

La conversión al cristianismo no modificó el concepto de la amistad, pero la nueva entidad sociológica iba a seguir su propia ley. En Tagaste la «comunidad» ya no era de amigos, sino de «monjes». La fuerte diferencia se aprecia en la correspondencia con Nebridio. Ya no son «intelectuales al servicio de la Iglesia, «sino combatientes en nombre de Cristo, al lado de la jerarquía». Los donatistas, con su odio, y los católicos con su aplauso, comienzan a darse cuenta de la importancia y relevancia de la institución monástica de Tagaste, cuya fama cunde. «El centro de gravedad del pensamiento de Agustín había comenzado a deslizarse» ${ }^{21}$.

Agustín es ordenado presbítero de Hipona. Mientras el monasterio de Tagaste, dirigido ahora por Alipio, va cobrando un auge insospechado, Agustín no renuncia a su título de monje. Recuerda casos de monjes elevados al presbiterado y quizá entre sus recuerdos, figure el caso de Eusebio de Vercelli, bien conocido en Milán. El hecho es que el santo funda en Hipona un monasterio muy cualificado y diferenciado. Va a convertirse en seminario, sin dejar de ser monasterio. Ni Agustín ni nadie había pensado hasta entonces en esa contigencia. Tampoco esta determinación puede ya influir para nada en la institución de Tagaste, pues eso sería un anacronismo retroactivo. Pero acontece algo más profundo: Agustín se entrega al estudio de la Biblia y se encuentra con la «teología de Pentecostés» de san Lucas (Hechos, 4,32). Por primera vez esa teología se presenta en un comentario de Agustín ${ }^{22}$. Pero no se habla aún de un solo corazón, sino de un «corazón simple», que se aplica a todos los cristianos, como en el libro De Sermone Domini in Monte.

El primer texto monástico que hace referencia a la teología de pentecostés es el de S. Posidio ${ }^{23}$. Y Posidio habla de la comunidad de bienes, pero no de la unión de los corazones. Y la comunidad de bienes era una necesidad impuesta en todo el mundo desde el principio del monacato; no era, pues, ningún carisma y tampoco ningún «ideal» específico de san Agustín, sino en todo caso un ideal universal monástico.

\footnotetext{
20. VERHEIJEN, l.c., p. 228, nota 111.

21. Brown, P., Augustine of Hippo, A Biography, London 1967, p. 134.

22. San Agustin, In ps. 4,10, PL 36, 83.

23. VERHEIJEN, l.c., p. 78.
} 
Y sin embargo estas modificaciones sustanciales no impiden ni cambian la importancia o el valor de la amistad en las comunicades monásticas, según san Agustín. Parece que la primera vez que Agustín comprende la importancia de esa «teología de Pentecostés», movido por san Paulino de Nola, quien le decía en una carta, hablando de sus emisarios Romano y Agil: «Ellos, deseo que lo creas, son con nosotros (Paulino y Terasia) un solo corazón y una sola alma» ${ }^{24}$. Agustín seguirá repitiendo, como siempre: «Buscamos a Dios y la vida bienaventurada». Para lograrlo era muy importante la institución monástica y para condicionar a ésta entraba la amistad, ya la específica de unos pocos amigos, ya la genérica de una confraternidad o si se quiere «caridad». La amistad era un accidente circunstancial y la misma institución monástica era un simple medio para lograr la «búsqueda de Dios y de la vida bienaventurada», o como en este tiempo comienza ya a especificar Agustín «para que los que viven no vivan para sí, sino para Aquel que murió por ellos» ( 2 Cor, 5,15). Aunque al parecer, la amistad de los monjes cambiaba de aspectos, en realidad y sociológicamente se afianzaba y consagraba la definición de la amistad. Porque se producía la coincidencia en los asuntos sagrados y profanos, en el servicio a la Iglesia y en la política clerical, en la reforma de las costumbres y en la más estrecha unión del pueblo con una jerarquía más evangélica. $\mathrm{Y}$ en cuanto a la «benevolencia y caridad» crecían hasta el punto de amenazar absorber del todo el concepto de la misma amistad. El carácter filosófico de Agustín impediría siempre, sin embargo, esa absorción.

Luego organiza Agustín en su propia Casa Episcopal un monasterio de clérigos, como origen de los «Canónigos regulares». Esto evidencia la capacidad de evolución de su institución monástica bajo el impulso del principio interno del Espíritu Santo. Así como los «seminaristas» de Hipona dejaban realmente de ser «monjes», así también dejaban de serlo los «canónigos regulares». Pero eso nunca le pasó a Agustín por las mientes, ya que su institución monástica era capaz de penetrar todas las células eclesiásticas, sin obstáculo alguno, mientras los hombres dieran vía libre al principio espiritual. El monaquismo es el instrumento de reforma de la Iglesia y Agustín obliga a su clero a pronunciar un voto de pobreza. Y no sabemos hasta dónde hubiera llegado Agustín, si hubiese podido desarrollar más su monaquismo.

Como se ve, el monaquismo de Agustín era excesivamente ambicioso, pues carecía de límites. No pretendía convertir la diócesis en un monasterio, un tanto a semejanza del monaquismo irlandés, sino viceversa, convertir los monasterios en instrumentos de reforma de la Iglesia, en reducir el monasterio

24. SAn Agustín, Epist. 30, entre las agustinianas, PL 33,122. 
a la diócesis. Esto era evidentemente una novedad, a pesar de los casos que pudiera conocer Agustín. Así no lo expresa san Ambrosio directamente:

«El monje se acostumbra a la abstinencia y a la fortaleza en una vida oculta y recogida, en la que lucha contra el apetito de la carne. En cambio, el clérigo lucha contra la barahúnda del siglo. El clérigo afronta y pisotea la molicie, mientras el monje la soslaya. La vida clerical es más digna, la monacal más segura. La una se reprime a sí misma, la otra se administra a sí misma. En ambas se practica la abnegación, pero la una entra en la refriega, mientras la otra se mantiene apartada. La una domina los incentivos, la otra los esquiva. La una resiste a la felicidad del mundo, la otra desprecia al mundo. La una está crucificada dentro del siglo, la otra es ignorada por el siglo. La una tiene mayores tentaciones y méritos, la otra menos caídas y más fácil vigilancia... Esta milicia angélica de los monjes se ocupa en la alabanza de Dios y en la oración; se entrega a la lectura y ocupa la mente con trabajos continuos, sin trato de mujeres, guardándose recíprocamente continua y estrecha vigilancia. Nada hay que temer y mucho que imitar en esta profesión» ${ }^{25}$.

Agustín sabía esto y lo confirma y repite ${ }^{26}$. San Ambrosio en la Epístola mencionada, celebra el caso de san Eusebio de Vercelli, que debía ser muy conocido en Milán, ya que con Eusebio compartió el destierro Dionisio, obispo de Milán y predecesor de Ambrosio. Pero las motivaciones de Agustín eran muy diferentes, sobre todo, después de adoptar la teología de Pentecostés, donde el consejo parecía convertirse en obligación, o por lo menos en ideal. Y la resistencia de los mismos obispos, cuando Agustín impuso al clero el voto de pobreza, indica que Agustín introducía una novedad muy discutible. ¿Por qué entonces Agustín reunió ambas profesiones y lo hizo con una convicción tan absoluta, como si fuese inspiración del Espíritu Santo, frente a toda resistencia? La respuesta es clara: si queremos hablar de «carisma fundacional» ese carisma era la «utilidad de la Iglesia» ${ }^{27}$; la utilidad de la Iglesia se convierte en criterio de todo posible cambio sociológico. Según lo reclamen las circunstancias y los tiempos o lugares. Y dentro de ese criterio habrá que hablar acerca de la amistad como secta y como milicia.

\section{LA DIMENSIÓN FILOSÓFICA}

La definición clásica de la amistad expresaba una dimensión filosófica, ordenando la amistad a la consecución de la felicidad y de la virtud. Agustín

25. S. Ambrosio, Epist. 63, 72s y 82s, PL 1,12,82ss.

26. San Agustín, Cfr. Epist. 48, PL 33,187s.

27. ID., Confess. IX, 8, 17, PL 32,771. 
mantiene esa misma relación, exigiendo además que la amistad sea verdadera, es decir, subordinada a una felicidad y a una virtud que sean «rectas» y "verdaderas». Esto es lo que manifestaban los Soliloquios, presentando el problema de la amistad a modo de ejemplo. Agustín ama a sus amigos, como ama la vida y la salud, le entristece el que algunos estén ausentes y celebraría de que estuviesen presentes, gozando con él de salud, concordia y ocio liberal ${ }^{28}$. Ama a los amigos para estudiar a Dios y al alma, suponiendo que la búsqueda entre varios significa multiplicar las posibilidades de descubrir. La amistad queda, pues, subordinada a la búsqueda de Dios y del alma. Si esos amigos rehúsan aceptar, Agustín trataría de persuadirlos. Si se muestran indiferentes, los retendría del mejor modo posible. Pero si se oponen o son obstáculo, es mejor que los abandone. Por ende es claro que la amistad queda condicionada por la finalidad de buscar ${ }^{29}$. Estamos, pues, dentro de la filosofía sapiencial de los clásicos, especialmente de Pitágoras: Agustín ama a los amigos, a la salud y a la propia vida tan sólo por razón de la sabiduría. Ésta es la razón de ser de la amistad ${ }^{30}$.

Pero la labor de Agustín era muy original. Por un lado retenía la misma definición de la amistad, que había recogido de Cicerón. Más aún, aceptaba la tesis de que tal amistad había de ser «verdadera», es decir, apropiada para conseguir la felicidad y la virtud. La dimensión filosófica permanecía intacta. Pero más importante que la filosofía era la religión, y la religión cristiana cambiaba la situación, al reclamar una felicidad verdadera y una virtud verdadera. Era claro para Agustín que una felicidad verdadera sólo podía conferirla Dios, el Dios verdadero, esto es, el Dios creador, personal y libre de los cristianos. También la virtud para ser «recta» y «verdadera» tenía que dirigirse intencionalmente a ese Dios cristiano. De ese modo la amistad pagana era al mismo tiempo verdadera y falsa, pues se mantenía la definición, pero se la cambiaba el contenido. Lo cual no es sorprendente en Agustín, ya que eso se realizaba en todo el frente de su pensamiento orgánico y unitario. Así surgen algunos problemas accidentales.

Agustín cambia la definición de las virtudes cardinales ${ }^{31}$ : las nuevas definiciones son caridad prudente, caridad fuerte, caridad templada, caridad justa. ¿Diremos que entonces la amistad es una «caridad amistosa»? Y en ese caso no quedará la amistad reducida a caridad. Pues bien, tal reducción es absurda, ya que cada virtud se define por su objeto formal. ¿Quién dirá que la li-

28. ID., Solil. I, 9,16, PL 32,878.

29. ID., Ibidem, I, 12,20, PL 32,881.

30. ID., Ibidem, I, 13,22, PL 32, 881 .

31. ID., De Mor. Ecl. I, 3, 4, PL 32,1312. 
mosna y la virginidad son la misma virtud porque ambas se reducen a la caridad? Lo que hace Agustín es otra cosa: dejando a cada virtud en su definición «objetiva», añade un común denominador «subjetivo», una referencia intencional a Dios. La amistad, pues, no cambia de definición y conserva todas sus funciones personales, pero si no es «recta y verdadera» no alcanzará la felicidad verdadera, porque tendrá un vitium de construcción mental, una desviación del objetivo o blanco «verdadero».

La trascendencia filosófica se cambia, pues, ahora en trascendencia personal, en referencia a un Dios personal. Pero éste sigue siendo un problema filosófico y no teológico, ya que los mismos clásicos subordinaban la amistad a una felicidad supuestamente verdadera. Nadie apetecía una felicidad falsa, y por eso la felicidad estaba siempre subordinada a la verdad, como ésta estaba subordinada a la unidad. Por eso Agustín combate y refuta a los filósofos. En efecto, Varrón contaba 288 sectas posibles y diferenciadas por su concepto de felicidad ${ }^{32}$, y Agustín no encuentra entre los filósofos una felicidad «verdadera», al poner las condiciones de esa felicidad ${ }^{33}$. Y la consecuencia es obvia: la amistad «verdadera» implica filosóficamente una referencia intencional a un Dios creador, libre y personal. El análisis de Agustín es ajustado. Los «bienes primarios de la naturaleza» (placer, tranquilidad, salud, hermosura, vivacidad de los sentidos, vigor de las potencias del alma, y la vida misma) pueden perderse en un momento o resultar inútil. Cicerón pretende consolarse con filosofías en la pérdida de su hija, pero sus consolaciones son meras declamaciones, ya que no tiene esperanza sobre la inmortalidad de su hija. Agustín sabía por la experiencia de la muerte de su amiguito de Tagaste el dolor que produce una muerte repentina.

El recurso a la virtud, aun en el mejor caso, que es el de los estoicos y platónicos, no vale mucho más. La virtud no es un bien primario y es preciso conquistarla a un alto y doloroso precio. $\mathrm{Y}$ aunque todo resultase bien, la virtud no nos libera de la ignorancia y de la concupiscencia: nos ayuda a luchar, pero no elimina la guerra interior y exterior. ¿Qué felicidad es ésta?, ¿dónde se encuentra en este mundo el «hombre feliz»? En ninguna parte ${ }^{34}$. He ahí, pues, la amistad condicionada por una felicidad y virtud «verdaderas».

Algunos críticos sugieren que al optar por el monaquismo, Agustín cae en el lazo de las dos morales que él reprochaba a los maniqueos ${ }^{35}$. pero precisamente Agustín no opone el «estado de perfección» de los monjes al «estado de

32. ID., De Civ. Dei, XIX, 1,1, PL 41,461.

33. ID., Ibidem, XIX, 6.4,1, PL 41,627.

34. ID., Ibidem, XIX, 4,3, PL 41,268.

35. ID., De Moribus Eccl. I,35,80, PL 32,1344. 
imperfección» de los cristianos, sino todo lo contrario: el monje es para él un simple cristiano lógico y consecuente. Nada vale para él la vieja objeción de Lutero: que los monjes se han reservado la perfección propia del cristiano. Las peculiaridades de la profesión monástica, reclamadas por el género de vida no significan una diferencia esencial: también las profesiones seculares se diferencian unas de otras como es natural. Todos los cristianos, incluidos los monjes, tienen un solo programa de perfección, que es el Sermón de la Montaña, como enseña Agustín, y como expresamente pone de relieve san Mateo. Pero san Lucas, al poner en boca de Cristo la fórmula «si quieres ser perfecto», no se refiere a la santidad o perfección religiosa, sino las condiciones de vida de un misionero, de un cristiano que tiene que dejar padre, madre, propiedades y quedar libre para «seguir a Cristo» de un modo especial, esto es, visitando las iglesias, como visitador volante o misionero apostólico, como lo reclamaban las condiciones de la primitiva Iglesia siríaca. Y esto implica una nueva casuística que Agustín respetó: a veces hay que abandonar a los amigos para servir a la Iglesia en otra parte. Nadie en la historia del monaquismo estuvo tan lejos de reservar a los monjes la perfección cristiana o de dispensar a los cristianos de las funciones y condiciones reclamadas por el bautismo que con frecuencia son más rigurosas que la misma disciplina monástica. La profesión religiosa es el sello que ponemos en el bautismo, exigiéndonos una obligación, pero no reservándonos un privilegio o arrogándonos una dignidad.

Otro capítulo discutido en Agustín ha sido la supuesta «moral de intención», a la que antes hemos aludido. Agustín acentúa que lo importante no es lo que cada uno hace sino cómo lo hace, es decir, con qué intención lo hace. Pero repetimos lo dicho arriba: Agustín no dice que el matar a un hombre con buena intención sea una cosa buena, o absurdos semejantes. Lo que ocurre es que el cristianismo cambia en cierto modo la noción de «pecado». Ya no se trata de acciones «objetivas»: por ejemplo, para un griego un homicidio es un homicidio, aunque se cometa sin libertad o sin conocimiento; para el cristianismo es un homicidio «material» pero no un «pecado» si se comete sin conocimiento o libertad. Y esto es aplicable a la amistad, no sólo por razón de su «verdad», sino también por razón de su «moralidad subjetiva». Una mala intención puede envenenar una amistad que aparentemente es perfecta, como una esposa puede ser infiel a su marido, aunque cumpla bien sus deberes matrimoniales.

¿Podríamos pensar en esa supuesta «síntesis posible y feliz» entre éros y agapè, siguiendo la teoría luterana de A. Nygren ${ }^{36}$. El elemento determinante

36. Nygren, A., Eros et Agapè, 3 vols. Paris 1962. 
sería un eudemonismo aristotélico, un egocentrismo o egoísmo. La caritas agustiniana sería una forma superior de la cupíditas. Por eso, J. Burnaby ${ }^{37}$ descartó y refutó cumplidamente a Nygren. En 1971 ambos volvieron a confrontar sús posiciones, pero con el mismo resultado, ya que la postura de $\mathrm{Ny}$ gren es solo un prejuicio luterano ${ }^{38}$. Sorprende, pues, la generosidad del $\mathrm{P}$. Viñas. Se ve que Lutero no había consultado en Cicerón las fórmulas frui amicis, frui otio, frui solitudine, etc.

¿Pero, y el «pesimismo» de Agustín acerca de la amistad y del amor humano? Cabía esperar que al meditar que todas las cosas de la creación son buenas y que todo es limpio para los limpios, debería haber acentuado el optimismo de su primera época ${ }^{39}$. En cambio, comienza a prodigar sus reservas. Así recoge el sarcasmo de Terencio: «Me casé y qué miserias me encontré. ¡Nacieron los hijos y cuántas preocupaciones! ${ }^{40}$. ¿Y qué es el amor humano? «Injurias, sospechas, enemistades, guerras, nuevas reconciliaciones, y vuelta a empezar» ${ }^{41}$. Agustín subraya: «Esto se da también en el honesto amor de los amigos» ${ }^{42}$. No podemos ver el corazón del amigo, y por lo mismo nada «sabemos» acerca de la pureza de su amistad. Nos apoyamos sólo en una creencia o en una credulidad: «¿quiénes suelen o deben ser más amigos que los que moran juntos en una misma casa? Y sin embargo, ¿quién de ellos está seguro? ${ }^{43}$. Cicerón había advertido que el peor enemigo es un amigo falso ${ }^{44}$, y Agustín ensombrece más la perspectiva citando el Evangelio: «y los enemigos del hombre son sus domésticos» (Mt 10,36).

Mucho se ha discutido sobre ese pesimismo, que muchos califican de realismo y aun de optimismo. Es una actitud general de Agustín frente al mundo, que aquí no vamos a discutir. Aquí bastará advertir que ese pesimismo no le impide cantar las excelencias de la amistad ni el vivirla y proveerla en aquel su ambiente de lucha, de fanatismo, de concilios, de violencias y terrorismos incesantes. Confiesa el intenso dolor que le produce el que alguna Iglesia lejana le reclame un amigo para utilidad superior ${ }^{45}$. El libro del P. Viñas nos ofrece un enorme cúmulo de textos probatorios. Agustín reconoce la labilidad y vulnerabilidad de las amistades humanas, pero eso es un caso de experiencia, y

37. Burnaby, J., Amor Dei. A Study of the religion of St. Augustine, London 1938.

38. Cfr. Lorenz, R., Fruitio Dei bei Augustinus, en «Zeitschr für Kirchengeschichte 63 (1950 y 1951) 75-132ss.

39. San Agustín, De Civ. Dei, XIX, 5, PL 41, 631.

40. Terencio, Los Hermanos, 5,4,13.

41. ID., El Eunuco, 1,1,14.

42. San Agustín, De Civ. Dei, XIX, 5, PL 41,632.

43. ID., Ibidem.

44. Cíerón, In Verrem, II, 1,15 .

45. San Agustin, Epist. 84,1, PL 22,294. 
quizá cuando describe la contigencia de la amistad escribe bajo la impresión de algún fracaso experimental. Por otra parte, la amistad queda siempre subordinada a la felicidad verdadera, y por eso fracasan muchas amistades, como es obvio.

Se admira el P. Viñas de que los autores digan ideal, fundamento, idea básica, principio diferencial, talante peculiar y no digan como él «carisma fundacional». No debiera admirarse. Cada uno de esos términos tiene su significado propio y diferencial y no se trata de sinónimos. Responden a un estudio filosófico y natural del monaquismo. En cambio la fórmula «carisma fundacional» ostenta carácter teológico, y dentro de la evolución del pensamiento agustiniano es un anacronismo optimista que deberá ser evitado. El problema del Vaticano II se refiere a un «hecho diferencial», se llame como se llame, pero si se trata de la finalidad que un fundador persigue (enseñanza, misiones, hospitales, niños, enfermos, contemplación, reforma, ejemplo, etc.) no se puede decir que san Agustín haya instituido su monaquismo para fomentar la amistad o para vivirla. Aun en este sentido está muy por debajo de Pitágoras. Concibió la amistad como un «bien útil», una condición favorable para alcanzar la utilidad de la Iglesia en el terreno social y la consecución de la felicidad o de la salvación en el terreno individual. Esto sin embargo no nos impidirá a nosotros el hacer propaganda de la amistad, contribuyendo a que en los monasterios se cree un ambiente de calor humano, de entusiasmo, de ordenación a Dios y a su Reino, de amor al prójimo, ya no sólo hasta compartir los bienes materiales, sino hasta llegar a la perfección de la caridad que es dar la vida por los amigos.

Pero hay que marcar las distinciones. El monje puede tener sus amigos dentro y fuera del monasterio y puede amarlos ya por su propia amabilidad o bien por la utilidad de la Iglesia. Podrá tener uno o dos amigos dentro del monasterio, podrá ser amigo de todos en general, tomando la amistad en un sentido my amplio. Lejos de reprochar a los autores la diversidad de «términos» convencionales, hay que pedirles que precisen bien su pensamiento al exponer doctrinas de Agustín. Seguramente que la diferencia de términos convencionales no es «convencional», sino que implica diversidad de opiniones de fondo y de puntos de vista. Por eso la coincidencia es imposible.

Pero tampoco podemos caer en pesimismos. EI P. Rubio ${ }^{46}$ recordaba que cuando surgen tantas opiniones diferentes, se hace sospechosa la misma fuente que las causa y ocasiona. Pero la diversidad de opiniones no brota de la fuente manantial, sino de que cada autor toma el agua de su arroyuelo parti-

46. RuBIO, L., l.c., p. 3. 
cular: los arroyuelos vienen de la fuente, pero cada uno de ellos tiene ya su sabor, su historia, sus circunstancias, su evolución y su función diferenciadas. Si los «agustinos» no pueden ni deben renunciar al ideal de conformar su espiritualidad a la de san Agustín, a quien han elegido como "fundador», deberán afrontar estas discusiones. Porque seguramente en todas las diferentes opiniones hay un fondo de verdad, una verdad parcial que cada día deberá depurarse, con claridad y método, no con anacronismos y errores históricos.

\section{LA DIMENSIÓN TEOLÓGICA}

El término carisma ha cobrado en la teología actual un sentido amplio. Así se habla del carisma de los fundadores de congregaciones religiosas. El carisma es un don que el Espíritu Santo otorga a un fundador. En virtud de él el fundador, como inspirado, ve la situación de la Iglesia, concibe la fundación de una organización nueva, que va a interpretar el Evangelio de un modo especial o específico para hacer frente a una necesidad eclesiástica. Después de tantas especulaciones como ha provocado la doctrina del Vaticano II, esta doctrina parece clara, cuando se trata de los «fundadores» en el sentido técnico de la palabra. Pero ¿es san Agustín un fundador técnico? Ya hemos visto en qué sentido podríamos llamarlo «fundador de los «agustinos». Y en ese caso el carisma de Agustín no era para los agustinos sino para los monjes de su tiempo, para todos los monjes en general. En este sentido decía Przywara que Agustín es el «fundador de todas las Órdenes religiosas de Occidente, desde la Orden de san Benito hasta la Compañía de Jesús» ${ }^{47}$ : «es la escatología de la misión: el ethos de la humildad, de la pobreza, de la indiferencia, por el que Agustín es el padre de la religiosidad específica de las grandes familias religiosas de Occidente, desde la Orden de san Benito hasta la Compañía de Jesús. Es la escatología de la oración sacerdotal: no son del mundo, pero son enviados al mundo». Éste sería, según Przywara, el carisma fundacional de Agustín. Pero el mismo Przywara se encarga de señalar que ese carisma monástico es solo parte de otro carisma superior, por el que Agustín es «padre de todos los 'agustinos' de Occidente». Y afinando todavía más, proclama un «agustinismo formal» que consistiría en establecer la necesidad de la revelación y por lo mismo la necesidad de la fórmula «crede ut intelligas». Y éste sería el carisma principal de Agustín, que proclama Przywara, aunque sea discutible, en la confrontación con la «religión racional» que buscaba Agustín durante toda su vida.

47. Przywara E., Augustinus, Die Gestalt als Gefüge, Leipzig 1934, p. 19s. 
El P. Viñas trata de identificar la amistad con la caridad, pero entonces ese es el "carisma fundacional del Evangelio», el «carisma fundacional de Cristo», y precisamente eso es lo que reprochaba Lutero a los religiosos y a los votos monásticos: el constituirse en «ejército profesional», cuando todos los cristianos viven en un «estado de perfección, como lo repetía sin cesar san Agustín en sus Sermones al pueblo cristiano.

No nos parece acertado recurrir a la Regula ad servos Dei para demostrar un «carisma fundacional». Aparte las opiniones sobre esa Regla, lo menos que puede exigirse es que se precise la fecha de su publicación. Porque si en la fundación de Agustín no existía tal Regla ¿cómo se la cita como prueba o testimonio?

Ya hemos dicho que la teología sólo cobra importancia con la fundación del monasterio de Hipona, acabada ya la obra de la fundación agustiniana. Entonces Agustín llega a creer que la teología de Pentecostés de san Lucas (Hechos 4,32) significa un monaquismo en la primitiva Iglesia. A ello le ayudaba el mismo san Lucas con su interpretación influida por el helenismo, y el concepto de las sectas filosóficas. En consecuencia, la amistad no pierde nada de su papel o de su función, pero tampoco gana nada. Queda como estaba. Y entonces, el problema se reduce a nuestra actualización o interpretación del pensamiento agustiniano.

Con frecuencia se exagera el espiritualismo de san Agustín, para crear conflictos con la jerarquía, con la institución, con el mundo sensorial, como si se tratase de un auténtico platonismo. Y esto puede hacerse ahora con la amistad. Vemos, por ejemplo, que mientras se reclama en la amistad un «calor humano», luego se pide que la amistad sea «verdadera» y ese «verdadera» se entiende como «virtud sobrenatural», que sería objeto de fe, de revelación, pero no de experiencia o de «calor humano». Si se convierte la amistad en una virtud infusa, en un puro «don sobrenatural», es inútil luego lamentarse de que se produce una excisión entre el orden natural y el sobrenatural, ya que ambos órdenes son diferentes, se diga lo que se diga. También se exagera a veces el extremo contrario, pidiendo a la amistad el calor humano, la comprobación experimental, la visibilidad. Pero entonces la amistad puede convertirse en rival y enemiga de la caridad, de la comunidad, de la convivencia, del espíritu monástico: dos amiguitos que dentro del monasterio se cierran para vivir su vida frente a la comunidad, no serían modelos de un «carisma fundacional». Por eso, si la caridad fraterna asume las funciones de la amistad, ésta está ya de sobra. Y si la amistad asume las funciones de la caridad, ésta está de sobra y la amistad sería la propia de los terroristas y comprometidos en una fidelidad criminal: sería la conspiración de dos o tres contra la caridad.

Que la amistad sea un don de Dios en sentido amplio no lo duda nadie. 
La misma «vida bienaventurada», a la que se subordina la amistad, es el don de Dios por excelencia ${ }^{48}$. Tal afirmación vale contra los que atribuyen la causalidad de la amistad a la fortuna, a la necesidad o al destino, como parecía defender Manlio Teodoro frente a Agustín ${ }^{49}$. Pero no vale para excluir las causas segundas, puesto que la providencia se vale de esas causas segundas. No se debe, pues hablar de la amistad como "don sobrenatural», sino como expresión «natural». El don de Dios respeta las leyes naturales. Los santos cultivaron sus amistades dentro y fuera del monasterio, y esas amistades eran perfectamente «naturales». Sirvan de ejemplo santa Teresa y el mismo san Agustín. Amistad y caridad son muy diferentes.

De nada sirve, pues, añadir que la amistad, que se identifica con la caridad, es la «verdadera», ya que según hemos visto, la amistad verdadera es la filosófica, y ésa se da en todas las religiones, sectas y aun entre los salteadores de caminos. Esto significa que la teología respeta la definición clásica de la amistad, aunque la llene de contenido cristiano o «sobrenatural», ya que atiende a su expresión natural. El problema que aquí se plantea entre lo natural y lo sobrenatural no afecta a las realidades naturales. Cuando Agustín afirma, por ejemplo, que su conversión fue obra de la gracia divina, esa afirmación no impedirá que también fuera obra del subconsciente, del cual se valió la gracia divina. Y lo mismo ocurre con la amistad. Una comunidad donde la amistad se manifiesta con el espíritu de secta, con su calor humano, con su capacidad de contagio, con su oferta de comunicación, fraternidad, confianza, entusiasmo y alegría, como la alegría o agalíasis de los primeros cristianos, esta claro que san Lucas atribuye ese gozo el Espíritu Santo, desde un punto de vista teológico (Hechos 2,46). Pero sociológicamente esa alegría «carismática» tiene su explicación «natural», como tiene también una explicación psicológica y una explicación filosófica. La teología no niega los aspectos «naturales o las causas naturales, sino que añade una causa superior y misteriosa solo es objeto de la fe. No es lícito recurrir al sofisma de confundir la amistad verdadera con la caridad sobrenatural.

Si se identifica la amistad verdadera con la caridd o la fraternidad, hay que entenderlas en el pensamiento orgánico de san Agustín como derivación del dogma de la filiación divina de todos los hombres. Todos somos hermanos de Cristo y en Cristo, sin distinción de monjes y seglares. La «comunidad» es la Iglesia, no la Geimeinschaft germánica. Repetimos que en tiempo de san Agustín no había «Órdenes religiosas» y por lo mismo no había «carismas fundacionales», y todos eran el «pueblo de Dios». No había, pues «hermanos

48. De Beata Vita, 1,5, PL 32962.

49. ID., Ibidem. 
de san Agustín, «órdenes de pobreza evangélica», «fraternidades apostólicas» ni «órdenes mendicantes», ni «ermitaños de san Agustín». Otra vez se nos exige optar por san Agustín o por Jordán de Sajonia. Mientras las nuevas constituciones juegan con estas «confraternidades» se va imponiendo la fórmula del papa Pablo VI al Capítulo General de nuestra Orden: «Procurad conservar fielmente, y hacerlo cada día más fructífero y, donde sea necesario, resucitadlo, el carisma propio de vuestra Orden» ${ }^{50}$. ¿Cuál es entonces el «carisma del fundador?» Parece que nadie se atreve a negar que ese «fundador» ha de ser san Agustín. ¿Cuál es entonces el «carisma de san Agustín? A esto el P. Viñas responde con una recensión de muy diferentes opiniones, que evidencian una confusión, que nunca se ha tratado de eliminar o discutir con calma. Está, pues, sin resolver. ¿Y qué logra Viñas con su nueva tesis? Añadir una opinión más a las ya existentes. Y ¿cómo demuesta su tesis? Propone tres proposiciones: 1) La verdadera amistad es un don del Espíritu, según san Agustín. Esto es claro desde un punto de vista teológico, lo cual no impide que haya amistades verdaderas aun entre los ladrones. Cuando Agustín expresa que las amistades no cristianas son «falsas» se refiere a su ordenación a un Dios creador, personal y libre, como ya vimos, pero sin tocar la definición clásica de la amistad verdadera. Y si en este punto excluimos la amistad «natural» estamos ya perdidos, pues la amistad verdadera será una virtud infusa y por lo mismo objeto de la fe, no de la experiencia. 2) La verdadera amistad, clave interpretativa del Evangelio, según san Agustín. Esto significa que se dirige a todos los cristianos, no a los monjes. Y significa que esa clave es la caridad, no la amistad. Hasta qué punto podemos recurrir al sofisma de identificar la amistad con la caridad universal, ya lo hemos dicho: es un mero sofisma. Tenemos que amar, no a los amigos, que eso lo hacen los fariseos y publicanos, sino a los enemigos. De hecho, los textos citados por Viñas no se refieren a los monjes, sino a todos los hombres y a los cristianos en especial. 3) La «verdadera amistad», expresión cabal del carisma agustiniano. Y para demostrarlo, se recurre a la Regula ad servos Dei. Además, reconoce que en ningún otro texto agustiniano se enuncia una descripción tan completa de una supuesta «amistad verdadera», sino sólo frases sueltas y fragmentarias, equivalentes. Y por fín, reconoce que tales expresiones podía Agustín leerlas en Cicerón, en el De amicitia. Pero esta argumentación es demasiado vulnerable, ya que se dan por supuestas demasiadas cosas: «No entraremos aquí en el estudio de la autenticidad de la Regula ad servos Dei, que suponemos suficientemente probada por toda erudición especializada» ${ }^{51}$. Sin embargo, se trata de una hipótesis, no de

50. Acta OSA, 16 (1971) 94.

51. VIÑAS, l.c., p. 247. 
una prueba suficiente de la erudición. Además, se supone que se puede aducir la Regula, escrita ciertamente después de la fundación del monasterio de $\mathrm{Hi}$ pona, para demostrar lo que Agustín pensaba en Milán, en Casiciaco y en Tagaste cuando fundó su monaquismo y poseía el «carisma fundacional». Lo curioso es que Viñas acepte la fecha propuesta por A. Manrique (años 426427), para que el anacronismo sea más sorprendente. Manrique estimaba que esa Regula es un documento particularísimo y circunstancial para el monasterio concreto de Hadrumeto, pero eso es una nueva hipótesis sin consistencia. Para aumentar nuestra sorpresa, Viñas añade otra hipótesis, a saber, que esa Regula antes de ser redactada para Hadrumeto, corría ya como selección de textos de las obras agustinianas. El anacronismo llega al colmo, cuando Viñas cita la teoría que expone U. Domínguez del Val, a saber: que Agustín escribió dos Reglas, una breve en Tagaste y otra larga para Hadrumeto o Hipona. Porque en ese caso se quiere explicar la coincidencia de la Regula con otros textos agustinianos. Pero esos textos, por ejemplo los del De Opere Monachorum serían muy posteriores a la Regula y entonces Agustín tuvo que adivinar lo que iba a escribir muchos años más tarde. ¿No son suficientes estas confusiones para anular del todo la argumentación que Viñas considera «la principal»?

Yo pienso que éste no es el camino para convencer a nadie. Y como el propósito de Viñas me parece excelente y quizá necesario, todos deberemos colaborar en que su propósito se realice sin anacronismos ni errores históricos. Creo, pues, que el camino es recurrir al sentido acomodaticio. Somos nosotros los que hemos optado por designar a san Agustín como «fundador» en un sentido amplio, y así nos hemos comprometido a estudiar y asimilar o vivr su espiritualidad monástica, dentro de su espiritualidad total cristiana. Así seguiremos los pasos de nuestros padres y hallaremos en san Agustín una fuente perenne de inspiración y renovación incesante. $\mathrm{Y}$ lo que vale para todas las congregaciones, tiene para nosotros un valor especial, a saber: siempre será necesaria una «actualización», un aggiornamento, es decir, una traducción e interpretación del pensamiento agustiniano, pues no en vano han pasado quince siglos, desde que él nacio. Esto no es un óbice, pues lo estamos haciendo siempre. Incluso con el Evangelio mismo. $Y$, por el contrario, es una ventaja, pues nos permite ser fiel al espíritu agustiniano y dejar a un lado ciertos detalles coyunturales que nos ofrece la misma Regula ad servos Dei, como acontece con la organización general de las decurias, con los baños, vestidos, salidas de casa de dos en dos, etc. Se mantiene mejor el espíritu de libertad o la libertad de espíritu de san Agustín.

El éxito de la institución monástica parece demostrar el gran papel que la amistad jugó en los monasterios de Agustín. En torno a él se reunieron muchos de los funcionarios romanos, hombres serviciales, agentes de negocios, 
que sabían luchar y se trataban muy bien con las autoridades romanas. Estos grupos selectos contrastaban con las jerarquías donatistas, tribales, aldeanas, inadaptadas, de manera que el catolicismo tomó con Agustín y sus amigos la iniciativa de la lucha y de las victorias incesantes. San Posidio da testimonio de dicho éxito, y de que Agustín dejó las iglesias llenas de un clero bien seleccionado, reclutado y formado. La amistad entre estos «funcionarios» y su relación con las autoridades civiles es bien manifiesta. Esto, claro está, obliga a tomar la amistad en un sentido amplio. Los amigos han de ser pocos, si han de ser «íntimos». Y en un monasterio, en virtud de la fraternidd, todos tienen que ser amigos. Y ningún religioso puede sentirse obligado a adquirir amigos porque lo ordena la Regula ad servos Dei, sino quizá porque lo recomendaba Pitágoras. Y en ese caso, tales amigos pueden estar fuera y no dentro del monasterio, come muchos de los amigos de Agustín.

El espíritu monástico debe encuadrarse en el espíritu evangélico y así la amistad monástica está subordinada a la caridad fraterna de todos los cristianos. Ésta lo abarca todo, bienes externos e internos, familia, tribu, la propia madre y la propia vida, hasta dar la vida por los «amigos» esto es, por los «hermanos» ${ }^{52}$. El escándalo que produjo a Lutero el que los «religiosos» se reservaran el estado de perfección, se ha extendido en nuestros días. Desde que el cardenal Mercier comenzó a predicar que el sacerdocio y el episcopado eran «estados de perfección» superiores al monaquismo, hasta la hora actual en que todos hablamos de «estados de perfección» y de la «perfección de todos los estados», las discusiones no han cesado, pero ya es imposible dar marcha atrás. La profesión religiosa sólo tiene sentido como formalización de las promesas del bautismo. Y para algunos teólogos esto es algo muy excelente, ya que permite afirmar que la profesión religiosa es un «sacramento» en cuanto formalización del sacramento del Bautismo.

Pero repetiremos que la teología no desdeña la amistad, sino que la perfecciona y realiza. Lo que pedimos es que en los monasterios reine un espíritu de amistad, propio de sectas, espíritu sensible y entusiasta, caluroso y notorio, experimental y alegre, sin que ese espíritu de amistad pretenda esconderse en una «caridad sobrenatural», que nadie puede comprobar sino creer. Y aquí es donde Viñas tiene toda la razón y donde probablemente volverá a insistir, ya que lo lleva en el corazón.

52. Cfr. Dideberg, l.c., p. 107. 


\section{CONCLUSIÓN}

La amistad es un fenómeno psicológico, que puede definirse como relación amorosa entre dos personas, «tú a tú», y que se funda en la amabilidad de las mismas personas. Ordinariamente va subordinada a la consecución de los valores más altos de la vida. Los clásicos la definieron como «coincidencia en los asuntos sagrados y profanos con benevolencia y caridad». Es una definición vaga, pues en ella caben muchas relaciones de diferente tipo. La amistad es una vivencia experimental y por eso no cabe en definiciones generales, como todo «enamoramiento». Se produce una adhesión o unión intencional y comprometida que equivale a un contrato o juramento de fidelidad. En cuanto doctrina o concepto puede ser más o menos estricta. Hay amistades íntimas de personas contadas y calificadas. Hay también un espíritu amplio de amistad que conviene a grupos, minorías y comunidades. En el primer caso el fenómeno es de carácter principalmente psicológico y en el segundo de tipo sociológico. Dentro de esos dos tipos caben mil clases de amistades, diferentes por sus motivaciones y por la idiosincrasia y circunstancias de sus personas.

En principio la amistad brota de la inclinación natural a amar y ser amado, aunque luego se añadan las motivaciones especiales. Pero en el caso de la amistad se crea un vínculo estable, una suerte de compromiso de fidelidad, que se convierte en un deber u obligación, esto es, en un yugo más o menos pesado o ligero y agradable.

Así en la actualidad se produce una paradoja: la sociedad de consumo tiende a disolver todo compromiso, entabla todo vínculo orgánico, que no corresponda a su organización y administración. Hay pues, una difusa, pero eficaz campaña contra la amistad, el matrimonio, los votos religiosos, las relaciones organizadas y totalitarias, para imponer vínculos en que las funciones se distribuyen y limitan según los intereses de las empresas, de la producción, y de la utilidad, sin entrar en la intimidad de la vida privada. Pero de ese modo el hombre actual ha caído víctima de dos grandes epidemos: no sabe soportar su propia soledad personal, huye de sí mismo buscando ruido, compañía irresponsable, distracción, contubernio, promiscuidad, masificación. Por otra parte, al desaparecer el concepto de prójimo o persona, el individuo se encierra en su egoísmo y trata de aprovechar los bienes circundantes, sin comprometerse: no sabe servir al prójimo, al que no mira como a un hermano, sino como a un competidor, rival, funcionario, clase, oficio, cliente, etc. En virtud de esa situación, el individuo busca la «secta» para comunicarse y ser comprendido, para identificarse y dignificarse. Así trata de sustraerse a la corriente de la sociedad de consumo y fomenta mil clases de organizaciones.

Las comunidades religiosas deberían ser el ambiente más apropiado para 
salvar hoy el personalismo y libertad del hombre. Por desgracia en virtud de una concepción determinada de la ascética, la amistad ha sido calificada de «particular» y condenada como peligrosa, enemiga de la comunidad y separatismo. Una condenación tan absoluta es lamentable y ha privado tanto a los religiosos como a sus comunidades del calor humano, del desarrollo normal de la afectividad, envenenando a veces su interior, provocando reacciones negativas y dolorosas, secando el corazón, creando un ambiente de frialdad e indiferencia, que desdice mucho del espíritu evangélico y de la influencia del Espíritu Santo. Por eso en la actualidad se nota entre los religiosos pensadores una reacción en favor de la amistad, del ambiente de familiaridad y de confianza.

El P. Viñas pertenece a la serie de autores que luchan por favorecer en las comunidades un ambiente de amistad. Y para ello ha escogido a san Agustín como modelo y maestro de la amistad cristiana. Ya otros habían estudiado antes ese tema. Pero él ha querido llevarlo tan lejos como le permitían los datos históricos, y las instancias del Vaticano II, invitando a las Congregaciones a definir su identidad fundacional y a actualizarla según las circunstancias de hoy. Pero en el primer punto, el tema exigía una crítica más profunda y rigurosa sobre las amistades de san Agustín y sobre sus doctrinas. El llevar el tema tan adelante, exigía a su vez una crítica más precisa sobre lo que ha de llamarse «carisma fundacional» en una «fundación» tan específica como la agustiniana. Exigía también un estudio de contexto agustiniano, es decir, de la filosofía y de la teología en las que ha de colocarse la teoría del santo sobre la amistad. Exigía, además, fijar el lugar que ocupa el monaquismo en la concepción agustiniana de la Iglesia y del mundo. Y finalmente exigía un estudio de la redacción o comparación de otros conceptos filosóficos o teológicos, como amistad «verdadera», amistad «recta» o bien «caridad fraterna, concordia, unanimidad», etc. En conjunto el propósito del P. Viñas no puede ser más excelente, pero sus conclusiones inmediatas no pueden aceptarse por falta de precisión y sobre todo de anacronismos. Un nuevo artículo publicado por el autor sobre este tema, indica que no abandonará fácilmente su ideal. Esperemos, pues, que vuelva sobre el tema. El libro publicado ha sido un éxito de acogida y de venta, que indica la actualidad del tema, el interés del público y la claridad y fácil lectura del libro. Es posible que al profundizar sobre el asunto, el éxito sea menor, pero será más duradero y seguro, y desde luego más verídico.

L. Cilleruelo 